\title{
Novel Insights into the Molecular Mechanisms Governing Mdm2 Ubiquitination and Destruction
}

\author{
Hiroyuki Inuzuka, Hidefumi Fukushima, Shavali Shaik, and Wenyi Wei \\ * Department of Pathology, Beth Israel Deaconess Medical Center, Harvard Medical School, Boston, MA 02215 \\ Correspondence to: Wenyi Wei, e-mail: wwei2@bidmc.harvard.edu \\ Keywords: Ubiquitination, SCF, $\beta$-TRCP, Casein Kinase I, Mdm2, p53, DNA Damage, Phosphorylation, Cell Cycle \\ Received: October 9, 2010, \\ Accepted: October 18, 2010, \\ Published: October 20, 2010
}

Copyright: () Inuzuka et al. This is an open-access article distributed under the terms of the Creative Commons Attribution License, which permits unrestricted use, distribution, and reproduction in any medium, provided the original author and source are credited.

ABSTRACT:

The Mdm2/p53 pathway is compromised in more than $50 \%$ of all human cancers,
therefore it is an intensive area of research to understand the upstream regulatory
pathways governing Mdm2/p53 activity. Mdm2 is frequently overexpressed
in human cancers while the molecular mechanisms underlying the timely
destruction of Mdm2 remain unclear. We recently reported that Casein Kinase I
phosphorylates Mdm2 at multiple sites to trigger Mdm2 interaction with, and
subsequent ubiquitination and destruction by the SCF ${ }^{\beta-T R C P} \mathrm{E} 3$ ubiquitin ligase. We
also demonstrated that the E3 ligase activity-deficient Mdm2 was still unstable
in the G1 phase and could be efficiently degraded by SCF ${ }^{\beta-T R C P}$. Thus our finding
expands the current knowledge on how Mdm2 is tightly regulated by both self-
and SCF ${ }^{\beta}$-TRCP-dependent ubiquitination to control p53 activity in response to stress.
It further indicates that loss of $\beta$-TRCP or Casein Kinase I function contributes to
elevated Mdm2 expression that is frequently found in various types of tumors.

\section{INTRODUCTION}

Recent scientific advances clearly demonstrated that tumors arise in a progressive fashion through overexpression of certain set of oncogenes, concomitantly with loss of function mutations in key tumor suppressor proteins. Among the known tumor suppressor proteins, the p53 tumor suppressor attracts intensive research interest since its activity is lost or compromised in over $50 \%$ of all human tumors [1]. p53 exerts its tumor suppressor function mainly through its role as a transcription factor to activate a wide spectra of downstream target genes. The activation of these downstream targets in turn are responsible for p53-dependent cell cycle arrest or apoptosis upon a variety of cellular stresses [2,3]. Among the ever-growing list of p53 targets, key players include p21, which initiates both G1 and G2 cell cycle arrest by inhibition of cyclindependent kinases [4, 5]; Gadd45 and 14-3-3, which participate in G2 cell cycle arrest $[6,7]$; and Bax, which is responsible for the pro-apoptotic activity of p53 [8]. Different types of DNA damage signals and variations in the extent of DNA-damage triggers activation of a distinct set of p53 downstream targets, thus initiating different types of stress response [9]. Because of its crucial role in response to DNA damage, p53 is considered the guardian of the genome whose activity is critical for maintaining the integrity of the genome $[10,11]$.

Mdm2 is the major negative regulator of the p53 pathway

p53 activity is strictly regulated in cells to prevent inappropriate activation [12], which could result in either premature senescence or elevated apoptosis [13, 14]. Among all the identified negative regulators, Mdm2 plays a critical role in promoting p53 ubiquitination and subsequent destruction (Figure 1A) [15, 16]. The physiological significance of this layer of regulation is demonstrated by the fact that $\mathrm{Mdm} 2$ knockout mice are embryonic lethal due to elevated p53 expression and this lethality can be rescued by further inactivation of $\mathrm{p} 53$ [17].

Earlier studies showed that the inhibitory function of Mdm2 towards p53 relies mainly on its interaction with the $\mathrm{p} 53$ protein, a process that is subject to many layers of regulation (Figure 1B). In response to stresses such as DNA damage, activation of the ATM/ATR/CHK kinase pathway results in p53 phosphorylation at the Ser15 and 


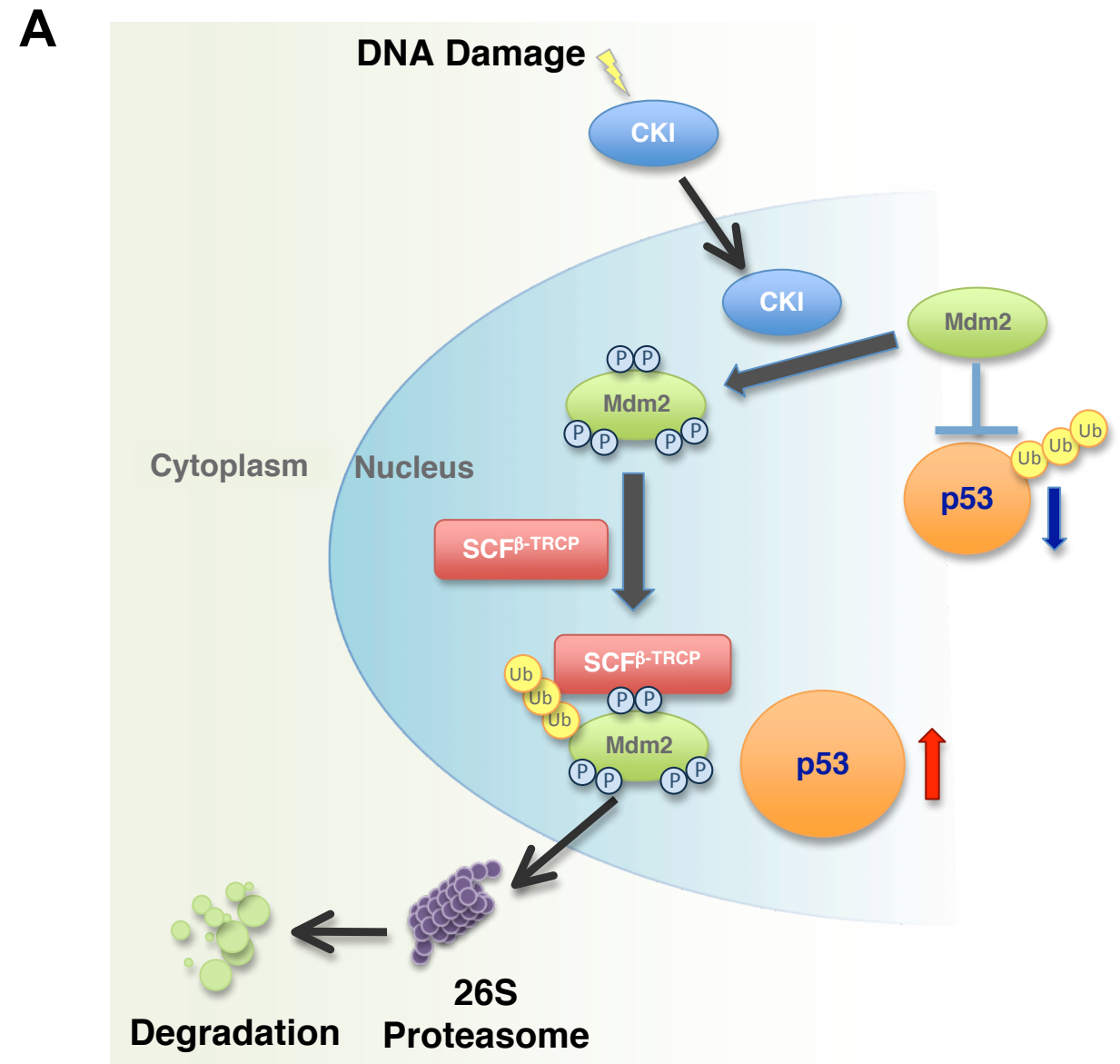

B

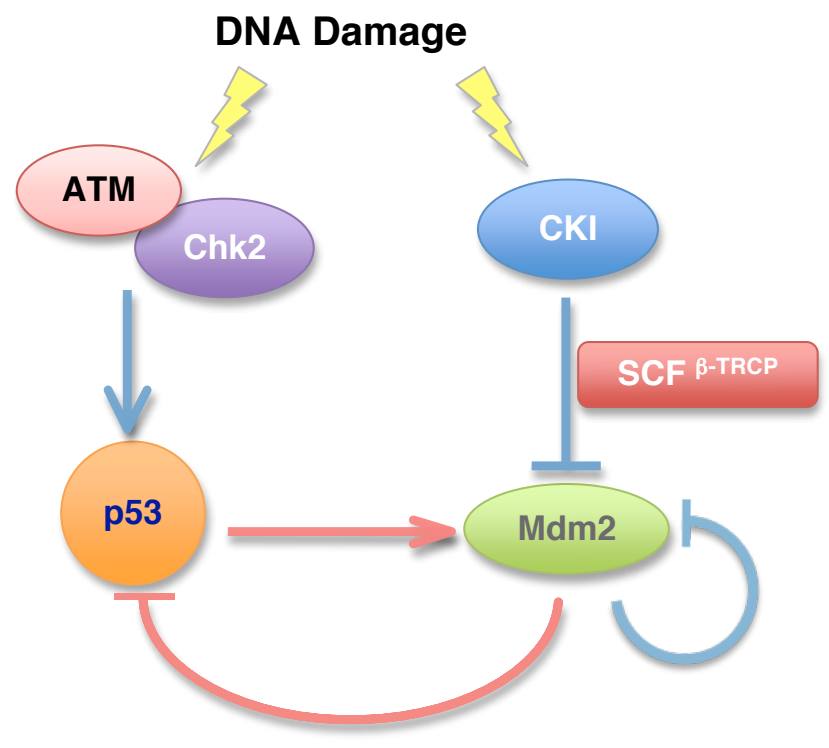

Figure 1: Multi-site phosphorylation of Mdm2 by Casein Kinase I triggers Mdm2 ubiquitination and destruction by SCF ${ }^{\beta-T R C P}$ in response to DNA damage.

A. In unstressed cells, p53 expression is maintained at basal level due to its interaction with Mdm2, which serves to promote p53 ubiquitination and subsequent destruction. In response to DNA damage, Casein Kinase I (CKI) translocates into the nucleus and phosphorylates Mdm2 at multiple sites. The phosphorylated Mdm2 species are recognized and ubiquitinated by SCF ${ }^{\text {-TRCP }}$, and subsequently degraded by the $26 \mathrm{~S}$ proteasome-dependent pathway.

B. p53 phosphorylation by ATM/Chk2 and Mdm2 phosphorylation by CKI positively regulate the p53 pathway. Phosphorylation of p53 by ATM/Chk2 triggers the dissociation of $\mathrm{p} 53$ from Mdm2 and stabilizes p53. However, increased p53 activity induces Mdm2 transcription, which serves as a negative feedback loop to induce p53 downregulation. On the other hand, in response to the genotoxic stress, the Mdm2 oncoprotein is quickly degraded by the $\mathrm{CKI} / \mathrm{SCF}^{\beta-\mathrm{TRCP}}$ signaling pathway. 
Ser20 sites, which serve to disrupt the interaction between Mdm2 and p53. In this setting, phosphorylated p53 can escape Mdm2-mediated proteolysis and accumulate to sufficient levels to initiate the stress response checkpoints $[18,19]$. Previous work indicated that Mdm2, the major negative regulator of $\mathrm{p} 53$, was also quickly degraded in response to DNA damage signals [20]. Hence the destruction of Mdm2 is essential to allow p53 to become stabilized and fully activated. However, the molecular mechanisms accounting for the rapid destruction of the $\mathrm{Mdm} 2$ protein following the DNA-damage response still remains unclear.

\section{Self-ubiquitination is not required for Mdm2 destruction}

Although it was previously proposed that Mdm2 undergoes self-ubiquitination when cells are treated with DNA damaging agents $[20,21]$, a recent study utilizing transgenic mice elegantly illustrated that the E3 ligase activity of $\mathrm{Mdm} 2$ may not be required for the destruction of the Mdm2 protein [22]. We also obtained experimental evidence showing that the ring-finger mutant Mdm2, which is defective in its E3 ligase activity, is still unstable in the early G1 phase and is quickly degraded after DNA damage. These results strongly suggest that the destruction of the Mdm2 protein, which is central in regulating the p53 pathway, is tightly controlled by a foreign E3 ligase.

\section{The $\mathrm{SCF}^{\beta-\mathrm{TRCP}} \mathrm{E3}$ ubiquitin ligase mediates $\mathrm{Mdm} 2$ destruction}

We recently reported a novel molecular mechanism by which CKI-mediated phosphorylation of $\mathrm{Mdm} 2$ at multiple sites triggers $\beta$-TRCP-mediated $\mathrm{Mdm} 2$ destruction (Figure 1A and 1B) [23]. Furthermore, we demonstrated that this mechanism operates both in response to DNA damage stress and in normal cell cycle progression, thus tightly controlling the abundance of $\mathrm{Mdm} 2$. As a result, Mdm2 expression is low in the early G1 phase, and becomes elevated when cells enter the S phase [24]. When endogenous $\beta$-TRCP was depleted, Mdm2 abundance was mainly upregulated in the midlate G1 phase. Correspondingly, the expression levels of p53 and its substrates p21 and Bax were reduced [23]. This indicates that $\beta$-TRCP-mediated Mdm2 destruction mainly operates in the mid-late G1 phase and that the fluctuation of Mdm2 might play an important role in cell cycle regulation through influencing the $\mathrm{p} 53 / \mathrm{p} 21$ pathway.

It is well recognized that most F-box proteins including $\beta$-TRCP, only interact with their substrates once they are properly phosphorylated [25]. Therefore, the regulation of substrate destruction mainly occurs at the level of the modifying enzyme, and for the case of Mdm2, we found that the activity of CKI determines the timing for Mdm2 destruction. In support of this notion, blocking CKI activity with a widely-used pharmaceutical inhibitor [26] resulted in a marked increase in the steadystate level of Mdm2 [23]. Previous research demonstrated that CKI activity is subject to many layers of regulation. For example, Wnt signaling has been shown to positively regulate CKI [27] while PKA is a repressor of CKI activity [28]. Additionally, autophosphorylation at the C-terminus by CKI attenuates its own kinase activity [29]. Our studies indicate that CKI activity might be relatively higher in the mid-late G1 phase, although the precise molecular mechanism is still unclear.

\section{The CKI signaling pathway is also involved in DNA damage-induced Mdm2 destruction}

In agreement with previous studies, we found that Mdm2 destruction was enhanced in response to DNA damaging treatment $[20,23]$. We also accumulated experimental evidence supporting the hypothesis that both CKI and $\beta$-TRCP are involved in this process. First, inactivation of $\beta$-TRCP by siRNA treatment partially blocked Mdm2 destruction after treatment with various DNA damaging agents. Secondly, inactivation of CKI by a widely-used pharmaceutical inhibitor blocked DNA-damage induced Mdm2 destruction. Furthermore, Mdm2 mutants whose putative CKI sites have been deleted displayed elevated levels of resistance to DNA damage-induced proteolysis. Although it was reported previously that CKI kinase activity is activated by DNA damaging signals [30], it is unclear how CKI is involved in controlling $\mathrm{Mdm} 2$ destruction after DNA damage. Our results argue that endogenous CKI activity was not significantly altered after DNA damaging treatment (data not shown). However, we found that DNA damage led to increased nuclear accumulation of $\mathrm{CKI} \delta$, which correlates with enhanced association between Mdm2 and $\mathrm{CKI} \delta$. These data indicate that DNA damage primarily modulates the accessibility of CKI $\delta$ cellular localization

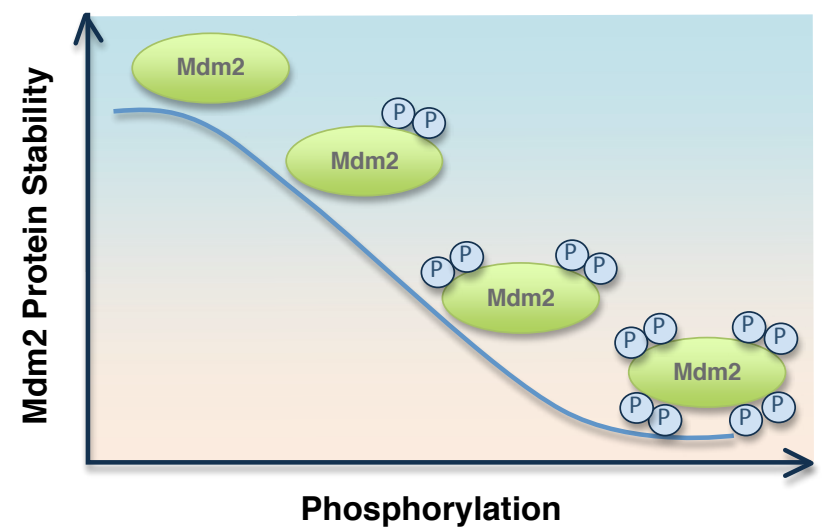

Figure 2: Inverse correlation between the extent of Mdm2 phosphorylation status and Mdm2 protein stability. CKI-mediated multi-site phosphorylation of Mdm2 determines Mdm2 stability in cells. 
rather than its kinase activity to influence Mdm2 stability (Figure 1A) [23].

\section{CKI-mediated multi-site phosphorylation of Mdm2 promotes its destruction by SCF $^{\beta-T R C P}$}

Using both mass spectrometry analysis and in vitro kinase assays, we demonstrated that the major CKI phosphorylation sites are located in the Mdm2 acidic domain (p2), while other minor CKI sites are located in the $\mathrm{N}$-terminal DSG site (p1) and the C-terminal SQ cluster (p3) region. In a search for major phosphorylation sites within those regions, we found that CKI phosphorylates Mdm2 at multiple sites, but we were not able to find any single point-mutation mutant that severely impaired CKI phosphorylation in comparison with the various deletion constructs. Interestingly, the loss of CKI phosphorylation in various Mdm2 mutants correlated very well with their reduced binding affinity, and subsequently their reduced destruction efficiency by $\beta$-TRCP1 [23]. This suggests that in contrast with other known $\beta$-TRCP substrates such as Emi-1 or Claspin, which contains one optimized canonical degron sequence, $\mathrm{Mdm} 2$ contains many suboptimized degron sequences that could be phosphorylated by CKI (Figure 2). It was found recently that many $\beta$-TRCP substrates including Cdc25A [31] and Gli3 [32-34] share the same feature by containing multiple degron sequences. A similar mechanism was first described for $\mathrm{SCF}^{\mathrm{Fbw}} 7$ to degrade its well-characterized substrate Sic1. Sic1 contained nine suboptimized degron sequences and phosphorylation of at least six of them are found to be required for initiating the destruction process [35]. It was further proposed that this multi-step phosphorylation might be a general mechanism to set a threshold for protein-protein interaction and thus create a strict switchlike transition [36]. Here, our studies suggested that the

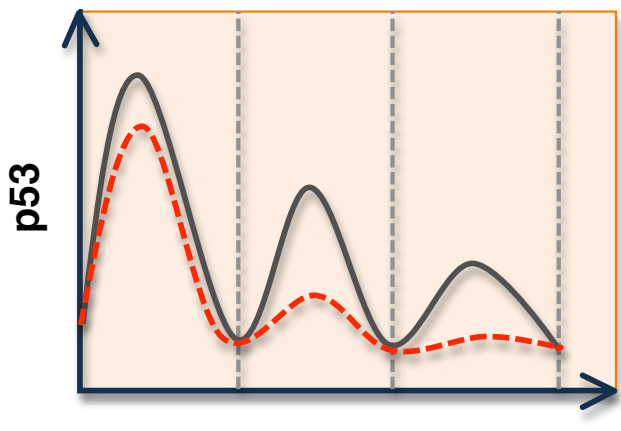

Time after DNA Damage cumulative, multisite phosphorylation of $\mathrm{Mdm} 2$ by CKI might set up a "dimmer switch" for Mdm2 destruction in response to DNA damage (Figure 2) [23].

\section{Both Mdm2 self-ubiquitination and $\beta$-TRCP- mediated ubiquitination contributes to $\mathrm{Mdm} 2$ destruction}

Mdm2 self-ubiquitination has been reported to play an important role in DNA-damage triggered Mdm2 destruction [20]. However, consistent with a recent report [22], we found that the ring-finger mutant (C464A) $\mathrm{Mdm} 2$ could still be efficiently degraded in response to various DNA damaging treatments. More importantly, ectopic expression of CKI and $\beta$-TRCP1 could efficiently destroy both the C464A mutant Mdm2 and the wildtype $\mathrm{Mdm} 2$, indicating the ring-finger activity of Mdm2 is not required for this process [23]. On the other hand, additional deletion of the $\mathrm{p} 2$ or $\mathrm{p} 3$ region greatly impaired $\beta$-TRCP-induced destruction of both wild-type Mdm2 and the C464A-Mdm2 mutant. These findings strongly imply that CKI-mediated phosphorylation, rather than the ringfinger domain of Mdm2, is critical for Mdm2 destruction after DNA damaging treatment.

On the other hand, we found that Mdm2 selfubiquitination played a critical role in regulating the steady state level of Mdm2 in cell cycle progression. This is demonstrated by the observation that the C464A Mdm2 mutant was more stable than wild-type $\mathrm{Mdm} 2$ during the cell cycle progression, especially in the mid-late G1 phase [23]. Interestingly, we found that depleting endogenous $\beta$-TRCP led to further upregulation of the C464A-Mdm2 protein. On the other hand, the Mdm2 mutant defective in CKI phosphorylation was much more stable as well, and its expression was not responsive to depletion of

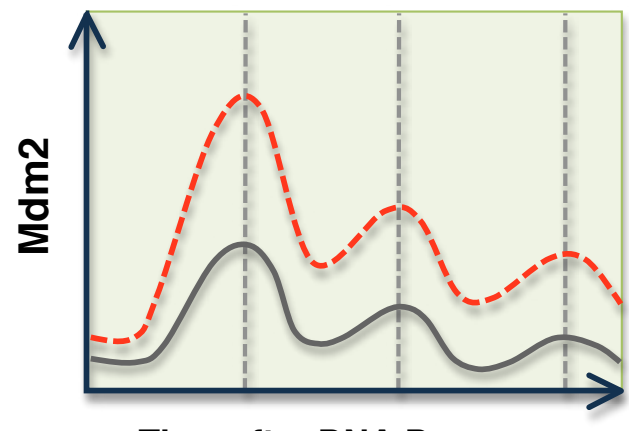

Time after DNA Damage

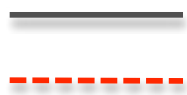

\section{Control siRNA \\ $\beta-T R C P 1+2$ siRNA}

Figure 3: Depletion of endogenous $\beta$-TRCP results in elevated Mdm2 levels, which subsequently suppress the amplitude of the p53 pulse in response to DNA damage. This further suggests that disruption of the CKI/SCF ${ }^{\beta-T_{R C P}}$ signaling pathway, which governs Mdm2 ubiquitination and degradation, might lead to misregulation of the p53 activity that contributes to cancer development. 
endogenous $\beta$-TRCP. Taken together, these data indicate that constitutive Mdm2 destruction during the cell cycle progression is tightly regulated by both self-ubiquitination and the $\beta$-TRCP-mediated ubiquitination pathways [23]. However, as our data suggested, the $\beta$-TRCP pathway might play a more important function in triggering $\mathrm{Mdm} 2$ degradation after stresses such as DNA damage.

\section{Loss of function mutation in either CKI or $\beta$-TRCP might contribute to $\mathrm{Mdm} 2$ elevation in tumors}

The Mdm2 protein has been characterized as an oncoprotein whose overexpression enhances cellular transformation. It is also widely accepted that Mdm2 is overexpressed in many types of tumors [37]. Although amplification has been found in many cases, the molecular mechanisms leading to elevated $\mathrm{Mdm} 2$ expression still remain unclear. Our studies suggested that dysfunction of the Mdm2 destruction pathway could potentially contribute to Mdm2 upregulation. This could be achieved by either inactivation of the responsible E3 ligase $\beta$-TRCP1 or by inactivation of the upstream modifying enzyme CKI. Alternatively, it could also be achieved by acquiring Mdm2 mutations that disrupt one or several of the multisite phosphorylation events by CKI. Indeed, deletion of $\beta$-TRCP1 has been reported in many types of cancers [38, 39]. Our data demonstrated that inactivation of $\beta$-TRCP1 resulted in significant upregulation of $\mathrm{Mdm} 2$, and subsequent downregulation of p53 activity. As a result, the cells are more resistant to DNA-damage induced apoptosis. Furthermore, our studies demonstrated that after depletion of $\beta$-TRCP, the oscillation of $\mathrm{p} 53$ expression in response to persistent DNA damage is affected (Figure 3) [23]. This result provided the molecular mechanism by which p53 activity can be dampered after depletion of $\beta$-TRCP. Altogether, this work suggests that a compromised Mdm2 destruction pathway might lead to subsequent Mdm2 stabilization, thus enhancing $\mathrm{Mdm} 2$ oncogenic activity by promoting p53 destruction and facilitating tumor progression. Therefore, our research provides insight into the underlying molecular mechanisms for the frequently observed Mdm2 overexpression in many types of tumors. This opens new avenues for the development of new anticancer drugs or regimens for treating cancer patients, especially those with elevated expression of the Mdm2 oncoprotein.

\section{CONFLICT OF INTEREST}

The authors have no conflict of interests to declare.

\section{ACKNOWLEDGEMENTS}

We thank Lixin Wan, Alan Lau and Pengda Liu for critical reading of the manuscript, and the other members of the Wei laboratory for useful discussions. W.W. is a Kimmel Scholar and V Scholar. Our studies of Mdm2 destruction were supported in part by the Massachusetts Life Science Center New Investigator award (W.W.), and by NIH grant GM089763 to W.W.

\section{REFERENCES}

1. Hollstein M, Sidransky D, Vogelstein B, Harris CC. p53 mutations in human cancers. Science 1991; 253:49-53.

2. Levine AJ. p53, the cellular gatekeeper for growth and division. Cell 1997; 88:323-331.

3. Harms K, Nozell S, Chen X. The common and distinct target genes of the p53 family transcription factors. Cell Mol Life Sci 2004; 61:822-842.

4. el-Deiry WS, Tokino T, Velculescu VE, Levy DB, Parsons R, Trent JM, Lin D, Mercer WE, Kinzler KW, Vogelstein B. WAF1, a potential mediator of p53 tumor suppression. Cell 1993; 75:817-825.

5. Bunz F, Dutriaux A, Lengauer C, Waldman T, Zhou S, Brown JP, Sedivy JM, Kinzler KW, Vogelstein B. Requirement for p53 and p21 to sustain G2 arrest after DNA damage. Science 1998; 282:1497-1501.

6. Wang XW, Zhan Q, Coursen JD, Khan MA, Kontny HU, Yu L, Hollander MC, O'Connor PM, Fornace AJ, Jr., Harris CC. GADD45 induction of a G2/M cell cycle checkpoint. Proc Natl Acad Sci U S A 1999; 96:3706-3711.

7. Chan TA, Hermeking H, Lengauer C, Kinzler KW, Vogelstein B. 14-3-3Sigma is required to prevent mitotic catastrophe after DNA damage. Nature 1999; 401:616-620.

8. Zhang L, Yu J, Park BH, Kinzler KW, Vogelstein B. Role of BAX in the apoptotic response to anticancer agents. Science 2000; 290:989-992.

9. Lakin ND, Jackson SP. Regulation of p53 in response to DNA damage. Oncogene 1999; 18:7644-7655.

10. Levine AJ, Finlay CA, Hinds PW. P53 is a tumor suppressor gene. Cell 2004; 116:S67-69, 61 p following S69.

11. Daujat S, Neel H, Piette J. MDM2: life without p53. Trends Genet 2001; 17:459-464.

12. Toledo F, Wahl GM. Regulating the p53 pathway: in vitro hypotheses, in vivo veritas. Nat Rev Cancer 2006; 6:909923.

13. Blaydes JP, Wynford-Thomas D. The proliferation of normal human fibroblasts is dependent upon negative regulation of p53 function by $\mathrm{mdm} 2$. Oncogene 1998; 16:3317-3322.

14. Mendrysa SM, McElwee MK, Michalowski J, O’Leary KA, Young KM, Perry ME. mdm2 Is critical for inhibition of p53 during lymphopoiesis and the response to ionizing irradiation. Mol Cell Biol 2003; 23:462-472.

15. Haupt Y, Maya R, Kazaz A, Oren M. Mdm2 promotes the rapid degradation of p53. Nature 1997; 387:296-299. 
16. Midgley CA, Lane DP. p53 protein stability in tumour cells is not determined by mutation but is dependent on Mdm2 binding. Oncogene 1997; 15:1179-1189.

17. Montes de Oca Luna R, Wagner DS, Lozano G. Rescue of early embryonic lethality in mdm2-deficient mice by deletion of p53. Nature 1995; 378:203-206.

18. Chehab NH, Malikzay A, Appel M, Halazonetis TD. Chk2/ hCds1 functions as a DNA damage checkpoint in $\mathrm{G}(1)$ by stabilizing p53. Genes Dev 2000; 14:278-288.

19. Hirao A, Kong YY, Matsuoka S, Wakeham A, Ruland J, Yoshida H, Liu D, Elledge SJ, Mak TW. DNA damageinduced activation of $\mathrm{p} 53$ by the checkpoint kinase Chk2. Science 2000; 287:1824-1827.

20. Stommel JM, Wahl GM. Accelerated MDM2 autodegradation induced by DNA-damage kinases is required for p53 activation. Embo J 2004; 23:1547-1556.

21. Stommel JM, Wahl GM. A new twist in the feedback loop: stress-activated MDM2 destabilization is required for p53 activation. Cell Cycle 2005; 4:411-417.

22. Itahana K, Mao H, Jin A, Itahana Y, Clegg HV, Lindstrom MS, Bhat KP, Godfrey VL, Evan GI, Zhang Y. Targeted inactivation of Mdm2 RING finger E3 ubiquitin ligase activity in the mouse reveals mechanistic insights into p53 regulation. Cancer Cell 2007; 12:355-366.

23. Inuzuka $\mathrm{H}$, Tseng $\mathrm{A}$, Gao $\mathrm{D}$, Zhai $\mathrm{B}$, Zhang $\mathrm{Q}$, Shaik $\mathrm{S}$, Wan L, Ang XL, Mock C, Yin H, Stommel JM, Gygi S, Lahav G, Asara J, Xiao ZX, Kaelin WG, Jr., Harper JW, Wei W. Phosphorylation by casein kinase I promotes the turnover of the Mdm2 oncoprotein via the SCF(betaTRCP) ubiquitin ligase. Cancer Cell 18:147-159.

24. Gu L, Ying H, Zheng H, Murray SA, Xiao ZX. The MDM2 RING finger is required for cell cycle-dependent regulation of its protein expression. FEBS Lett 2003; 544:218-222.

25. Petroski MD, Deshaies RJ. Function and regulation of cullin-RING ubiquitin ligases. Nat Rev Mol Cell Biol 2005; 6:9-20.

26. Rena G, Bain J, Elliott M, Cohen P. D4476, a cellpermeant inhibitor of CK1, suppresses the site-specific phosphorylation and nuclear exclusion of FOXO1a. EMBO Rep 2004; 5:60-65.

27. Swiatek W, Tsai IC, Klimowski L, Pepler A, Barnette J, Yost HJ, Virshup DM. Regulation of casein kinase I epsilon activity by Wnt signaling. J Biol Chem 2004; 279:1301113017.

28. Giamas G, Hirner H, Shoshiashvili L, Grothey A, Gessert S, Kuhl M, Henne-Bruns D, Vorgias CE, Knippschild U. Phosphorylation of CK1delta: identification of Ser370 as the major phosphorylation site targeted by PKA in vitro and in vivo. Biochem J 2007; 406:389-398.

29. Graves PR, Roach PJ. Role of COOH-terminal phosphorylation in the regulation of casein kinase I delta. J Biol Chem 1995; 270:21689-21694.

30. Santos JA, Logarinho E, Tapia C, Allende CC, Allende JE, Sunkel CE. The casein kinase 1 alpha gene of Drosophila melanogaster is developmentally regulated and the kinase activity of the protein induced by DNA damage. J Cell Sci 1996; 109 (Pt 7):1847-1856.

31. Kanemori Y, Uto K, Sagata N. Beta-TrCP recognizes a previously undescribed nonphosphorylated destruction motif in Cdc25A and Cdc25B phosphatases. Proc Natl Acad Sci U S A 2005; 102:6279-6284.

32. Pan Y, Bai CB, Joyner AL, Wang B. Sonic hedgehog signaling regulates Gli2 transcriptional activity by suppressing its processing and degradation. Mol Cell Biol 2006; 26:3365-3377.

33. Wang B, Li Y. Evidence for the direct involvement of \{beta\} TrCP in Gli3 protein processing. Proc Natl Acad Sci U S A 2006; 103:33-38.

34. Tempe D, Casas M, Karaz S, Blanchet-Tournier MF, Concordet JP. Multisite protein kinase A and glycogen synthase kinase 3beta phosphorylation leads to Gli3 ubiquitination by SCFbetaTrCP. Mol Cell Biol 2006; 26:4316-4326.

35. Nash P, Tang X, Orlicky S, Chen Q, Gertler FB, Mendenhall MD, Sicheri F, Pawson T, Tyers M. Multisite phosphorylation of a CDK inhibitor sets a threshold for the onset of DNA replication. Nature 2001; 414:514-521.

36. Ferrell JE, Jr. Six steps to destruction. Nature 2001; 414:498-499.

37. Momand J, Wu HH, Dasgupta G. MDM2--master regulator of the p53 tumor suppressor protein. Gene 2000; 242:1529.

38. Nakayama KI, Nakayama K. Regulation of the cell cycle by SCF-type ubiquitin ligases. Semin Cell Dev Biol 2005; 16:323-333.

39. Rayburn E, Zhang R, He J, Wang H. MDM2 and human malignancies: expression, clinical pathology, prognostic markers, and implications for chemotherapy. Curr Cancer Drug Targets 2005; 5:27-41. 